\title{
Gout after Living Kidney Donation: Correlations with Demographic Traits and Renal Complications
}

\author{
Ngan N. Lam ${ }^{a}$ Amit X. Garg ${ }^{a}$ Dorry L. Segev ${ }^{b}$ Mark A. Schnitzler ${ }^{c} d$ \\ Huiling Xiao $^{c}$ David Axelrod $^{e}$ Daniel C. Brennan ${ }^{f}$ Bertram L. Kasiske ${ }^{g}$ \\ Janet E. Tuttle-Newhall ${ }^{d}$ Krista L. Lentine ${ }^{c, d}$ \\ ${ }^{a}$ Division of Nephrology, Western University, London, Ont., Canada; ${ }^{b}$ Division of Abdominal Transplantation, \\ Department of Surgery, Johns Hopkins School of Medicine, Baltimore, Md., USA; 'Center for Outcomes Research, \\ Saint Louis University School of Medicine, and d Division of Abdominal Transplantation, Department of Surgery, \\ Saint Louis University School of Medicine, St. Louis, Mo., USA; ' Division of Abdominal Transplantation, Department of \\ Surgery, Dartmouth Hitchcock Medical Center, Hanover, N.H., USA; ${ }^{\text {T }}$ Transplant Nephrology, Washington University \\ School of Medicine, St. Louis, Mo., USA; and ${ }^{9}$ Division of Nephrology, Hennepin County Medical Center and University of \\ Minnesota, Minneapolis, Minn., USA
}

\section{Key Words}

Cohort study . Gout . Health administrative data . Health outcomes · Kidney disease - Living kidney donors . Pharmacy claims $\cdot$ Registries

\footnotetext{
Abstract

Background: The demographic and clinical correlates of gout after living kidney donation are not well described. Methods: Using a unique database that integrates national registry identifiers of U.S. living kidney donors (1987-2007) with billing claims from a private health insurer (2000-2007), we identified post-donation gout based on medical diagnosis codes or pharmacy fills for gout therapies. The frequencies and demographic correlates of gout after donation were estimated by Cox regression with left- and right-censoring. We also compared the rates of renal diagnoses among donors with and without gout, matched in the ratio $1: 3$ by age, sex, and race. Results: The study sample of 4,650 donors included $13.1 \%$ African Americans. By seven years, African
}

Americans were almost twice as likely to develop gout as Caucasian donors (4.4 vs. 2.4\%; adjusted hazard ratio, aHR, 1.8; 95\% confidence interval (Cl) 1.0-3.2). Post-donation gout risk also increased with older age at donation (aHR per year 1.05) and was higher in men (aHR 2.80). Gout rates were similar in donors and age- and sex-matched general nondonors (rate ratio $0.86 ; 95 \% \mathrm{Cl} 0.66-1.13$ ). Compared to matched donors without gout, donors with gout had more frequent renal diagnoses, reaching significance for acute kidney failure (rate ratio $12.5 ; 95 \% \mathrm{Cl} 1.5-107.0$ ), chronic kidney disease (rate ratio $5.0 ; 95 \% \mathrm{Cl} 2.1-11.7$ ), and other disorders of the kidney (rate ratio $2.2 ; 95 \% \mathrm{Cl} 1.2-4.2$ ). Conclusion: Donor subgroups at increased risk of gout include African Americans, older donors, and men. Donors with gout have a higher burden of renal complications after demographic adjustment.

C 2015 S. Karger AG, Basel

Institution at which work was performed: Saint Louis University, St. Louis, MO, USA.

\section{KARGER 125\%}

(c) 2015 S. Karger AG, Base

0250-8095/15/0413-0231\$39.50/0

E-Mail karger@karger.com

www.karger.com/ajn
Krista L. Lentine, MD, PhD

Saint Louis University, Salus Center 4th Floor

3545 Lafayette Avenue

St. Louis, MO 63104 (USA)

E-Mail lentinek@slu.edu 


\section{Introduction}

A decline in renal function results in less uric acid excretion and higher levels of serum uric acid $[1,2]$ contributing to a higher risk of gout in patients with chronic kidney disease (CKD) [3, 4]. To complicate this association, elevated serum uric acid levels have been implicated as a risk factor for the development and progression of CKD [4-7]. A recent systematic review and meta-analysis found that hyperuricemia was an independent predictor of newly diagnosed CKD in the non-CKD population [5].

Following donor nephrectomy, living kidney donors lose approximately $30 \%$ of their renal function [8]. Three previous studies have shown that serum uric acid levels commonly rise above pre-donation levels as early as 6 months after donor nephrectomy [9-11]. Recently, we found that living kidney donors from Ontario, Canada, were more likely to be diagnosed with gout compared to healthy matched non-donors ( 3.4 vs. $2.0 \%$; hazard ratio 1.6 ; $95 \%$ confidence interval (CI) $1.2-2.1 ; \mathrm{p}<0.001$ ) and were more likely to receive a prescription for a medication typically used to treat gout (3.8 vs. $1.3 \%$; odds ratio 3.2 ; $95 \%$ CI $1.5-6.7 ; \mathrm{p}=0.002$ ) over an average 8 years of follow-up [12]. One limitation of this study was the lack of available information on race/ethnicity. Since $75 \%$ of Ontario residents are Caucasian, these results may not be generalizable to non-Caucasian donors.

In the general population, African Americans have a higher risk of gout compared to Caucasians $[13,14]$. One sub-study of the Atherosclerosis Risk in Communities (ARIC) study assessed 11,963 participants, of whom 24\% were African American, and found that African American men and women had a higher risk of gout (assessed on the basis of self-reports of physician diagnoses) compared to Caucasians [14]. Among women, the adjusted hazard ratio for African American race was 1.7 (95\% CI 1.3-2.2) while among men the adjusted hazard ratio was 1.9 (95\% CI 1.4-2.6). African Americans had more risk factors for the development of gout including higher serum uric acid levels, higher prevalence of hypertension, and greater use of diuretics. Whether the risk of gout following living kidney donation varies by race is currently unknown.

While a decline in renal function post-donation may lead to hyperuricemia and a predisposition to gout, given the interplay between uric acid and renal function, it may be that hyperuricemia also contributes to renal disease post-donation. A recent single center study including 207 women found that, among female living kidney do- nors, a $60 \mu \mathrm{mol} / \mathrm{l}$ increase in pre-donation serum uric acid level was associated with a 1.7-times higher risk of $>25 \%$ decline in estimated glomerular filtration rate (GFR) at 6 months post-donation [15].

To advance the understanding of the demographic and clinical correlates of gout among a national sample of living kidney donors in the United States (U.S.), we examined a unique database that integrates national registry identifiers of living donors with billing claims from a private health insurer. Our primary aim was to identify post-donation gout and to investigate possible variation within donors according to demographic traits including race. We also compared gout among living kidney donors to that in age- and sex-matched, general population nondonors as one benchmark for framing the frequency of post-donation gout. Lastly, given possible associations between gout and kidney disease, we compared the rates of renal conditions among matched donors with and without gout.

\section{Methods}

Data Sources

We conducted a retrospective cohort study using linked healthcare databases in the U.S. to ascertain patient characteristics, covariate information, and outcome events. The Organ Procurement and Transplantation Network (OPTN) contains information on all donors, wait-listed patients, and transplant recipients in the U.S. The Health Resources and Services Administration (HRSA), U.S. Department of Health and Human Services provides oversight to the activities of the OPTN contractor. After approval from the Saint Louis University Institutional Review Board and HRSA, the unique OPTN identifiers for living kidney donors were linked using names and dates of birth to beneficiary identifiers from national private health insurer electronic databases. The insurer databases include information on providerreported diagnostic billing claims as well as pharmacy claims for prescription medications. Analyses were performed using Health Information Portability and Accountability Act-compliant limited datasets, with all direct identifiers removed. These databases have been used for epidemiologic and health services research including studies of living kidney donor outcomes [16-21]. Because of the large sample size, the anonymity of the patients studied, and the nonintrusive nature of the research, a waiver of informed consent was granted by the Department of Health and Human Services Code of Federal Regulations (Title 45, Part 46, Paragraph 46.116).

\section{Population}

We included living kidney donors who had donated between October 1987 and July 2007, and were enrolled in the insurance benefit plan at some point after donation during May 2000 to December 2007 (the period of available claims data). Persons who had not donated a kidney (non-donors) and were enrolled in the 
same insurance benefit plan at some point during the same time period (May 2000 to December 2007) were sampled as general population controls. All study participants were simultaneously enrolled in medical and pharmacy benefits with the insurer exclusively during the study period.

\section{Outcomes and Covariates}

The primary outcome was a composite of the first diagnostic billing claim for gout or pharmacy claim for a medication typically used to treat gout. Provider-reported gout diagnoses were identified by the corresponding International Classification of Disease, Ninth Revision, Clinical Modification (ICD-9-CM) code (274.x). Pharmacy claims for medications typically used to treat gout included allopurinol or colchicine; febuxostat was approved by the U.S. Food and Drug Administration in 2009 and was not captured in the study data. Components of the primary outcome were also analyzed separately. To examine possible correlations of gout with renal disorders after donation, renal condition diagnoses were also extracted based on ICD-9-CM diagnostic codes (see online suppl. Appendix 1; for all online suppl. material, see www.karger.com/doi/10.1159/000381291) and included nephrolithiasis, acute kidney failure, CKD, renal failure unspecified, and other renal disorders.

Baseline demographic information ascertained for living kidney donors from the OPTN at the time of donation included age, sex, and race as reported by the transplant center. The insurance records include information on age and sex, but not race; thus, race information was not available for non-donors. Times from donation to start and end of captured insurance benefits were based on OPTN-reported donation dates and insurance enrollment records.

\section{Statistical Analyses}

Datasets were merged and analyzed with SAS (Statistical Analysis Software) version 9.3 (SAS Institute Inc., Cary, N.C., USA). In all outcome analyses, we interpreted two-tailed $\mathrm{p}$ values $<0.05$ as statistically significant.

\section{Demographic Correlates of Gout after Living Kidney}

Donation

Because the observation period for the insurance benefit plan inclusion varied between donors, Cox regression with censoring was used to estimate the frequency of outcomes over time and evaluate any associations (adjusted hazards ratios, aHR) with donor characteristics, specifically race. Left-censoring was applied from donation to insurance benefit plan enrollment and right-censoring was applied at the end of the insurance benefits or the end of study period (December 2007).

\section{Comparison of Gout in Living Donors and General}

Non-Donors

To compare the burden of gout among the donors to a nondonor sample, donors were matched 1:1 with general insurance beneficiaries (non-donors) by age and sex when benefits began. The maximum observation time, defined by the duration of the insurance benefit plan in each matched pair, was limited to the shortest available in the pair. We compared diagnostic billing claims and/or pharmacy fill rates in donors and matched non-donors as rate ratios, as previously described $[17,18]$. Donor versus general population non-donor rate ratios were also computed after stratification by sex, and by time elapsed from donation to insurance enrollment as above or below the sample median ( 4.9 years). A schematic of the study design including matching of donors and non-donors, and assessment of study outcomes, is shown in online supplementary Appendix 2.

\section{Correlations of Gout and Renal Conditions after Living}

\section{Donation}

Living donors with gout (as defined by the presence of a diagnostic code for gout or a pharmacy fill for a medication typically used to treat gout) were matched 1:3 to donors without gout by age, sex, and race. We compared rates of renal condition diagnoses in the donors with and without gout as rate ratios. In such instances, the renal diagnoses could have occurred before or after the diagnosis or treatment of gout, but in all cases, both event categories occurred after kidney donation. Use of billing claims to study CKD [16] and a similar series of renal conditions in this live donor cohort have been previously described [21].

\section{Results}

\section{Baseline Characteristics of the Living Donor Sample}

The baseline characteristics of the 4,650 living kidney donors in the study cohort have been described earlier and were similar to that of all U.S. living kidney donors registered in the OPTN in the same period [16]. Among the donors, $76.3 \%$ were Caucasian, $13.1 \%$ were African American, $8.2 \%$ were Hispanic, and $2.4 \%$ were other races (table 1). The mean age at the time of donation was 37.2 years, and $45 \%$ were men. Most living kidney donors $(81.2 \%)$ were biologically related to their recipient. The median duration from donor nephrectomy to the start and end of the observed insurance eligibility were 4.9 and 7.7 years, respectively.

\section{Demographic Correlates of Gout after Living Kidney Donation}

By seven years post-donation, the cumulative incidence of a diagnostic claim for gout or a pharmacy fill for a gout medication in the donor sample was $2.5 \%$ (95\% CI 1.6-2.4\%). With age and sex adjustment, the seven-year incidence of gout was nearly twice as common among African American compared to Caucasian donors (4.4 vs. 2.4\%; aHR 1.8; 95\% CI 1.0-3.2; $\mathrm{p}=0.04)$ (table 1). There was no significant difference in the primary outcome between Hispanic donors and Caucasian donors (aHR 0.60; 95\% CI 0.19-1.9). The risk of a diagnosis of gout or a pharmacy fill for a gout medication rose by $5 \%$ with each increase in year of donor age (aHR 1.05; 95\% CI 1.031.07; $\mathrm{p}<0.0001)$. Post-donation gout was almost three times higher among male compared to female donors (aHR 2.80; 95\% CI 1.75-4.48; $\mathrm{p}<0.0001$ ). 
Table 1. Adjusted associations of baseline characteristics with risk of diagnosis of gout and/or pharmacy fill for a medication typically used to treat gout in U.S. living kidney donors

\begin{tabular}{lllll}
\hline Baseline characteristics & Trait distribution & \multicolumn{3}{c}{ Adjusted hazard ratio $^{\mathrm{a}}$} \\
\cline { 3 - 5 } & & $\begin{array}{l}\text { Gout diagnosis or } \\
\text { medication }^{\mathrm{b}}\end{array}$ & $\begin{array}{l}\text { Gout } \\
\text { diagnosis }\end{array}$ & $\begin{array}{l}\text { Gout } \\
\text { medication }\end{array}$ \\
\hline Age at donation (per year) & $37.2(10.0)$ & $1.05^{\mathrm{c}}$ & $1.06^{\mathrm{c}}$ & $1.05^{\mathrm{d}}$ \\
Male sex & $45.4 \%$ & $2.80^{\mathrm{c}}$ & $3.48^{\mathrm{c}}$ & $4.75^{\mathrm{c}}$ \\
Race & & & & Reference \\
Caucasian (non-Hispanic) & $76.3 \%$ & Reference & 1.68 & 1.69 \\
African American & $13.1 \%$ & $1.81^{\mathrm{e}}$ & 0.72 & 1.05 \\
Hispanic & $8.2 \%$ & 0.60 & 0.82 & 1.22
\end{tabular}

Data presented as percentages except for age, which is presented as mean (standard deviation). ${ }^{\text {a }}$ Adjusted hazard ratios estimated in living kidney donors by multivariate Cox regression with left- and right-censoring. b Post-donation gout defined by either a diagnostic billing claim for gout or a pharmacy fill claim for a medication typically used to treat gout. ${ }^{\mathrm{c}} \mathrm{p}<0.0001 .{ }^{\mathrm{d}} \mathrm{p}=0.0006 .{ }^{\mathrm{e}} \mathrm{p}=0.04$.

Table 2. Risk of gout diagnosis and/or treatment in U.S. living kidney donors compared with age- and sex-matched non-donors, overall and stratified by sex and by time from donation to start of insurance enrollment

\begin{tabular}{|c|c|c|c|}
\hline & \multicolumn{2}{|c|}{$\begin{array}{l}\text { Event rate per } 1,000 \\
\text { person-years }\end{array}$} & \multirow[t]{2}{*}{$\begin{array}{l}\text { Rate ratio } \\
(95 \% \mathrm{CI})\end{array}$} \\
\hline & Donors & Non-donors & \\
\hline \multicolumn{4}{|c|}{ Gout diagnosis or medication } \\
\hline Overall & 16.0 & 18.6 & $0.86(0.66-1.13)$ \\
\hline \multicolumn{4}{|l|}{ Sex } \\
\hline Men & 25.9 & 29.7 & $0.87(0.64-1.19)$ \\
\hline Women & 7.8 & 9.3 & $0.84(0.51-1.41)$ \\
\hline \multicolumn{4}{|c|}{ Time from donation to start of insurance enrollment, years } \\
\hline$\leq 4.9$ (early) & 10.5 & 18.2 & $0.58(0.38-0.88)^{\mathrm{a}}$ \\
\hline$>4.9$ (later) & 21.8 & 18.9 & $1.15(0.81-1.63)$ \\
\hline \multicolumn{4}{|l|}{ Gout diagnosis } \\
\hline Overall & 13.4 & 15.0 & $0.89(0.67-1.20)$ \\
\hline \multicolumn{4}{|l|}{ Sex } \\
\hline Men & 22.4 & 23.8 & $0.94(0.67-1.32)$ \\
\hline Women & 5.8 & 7.5 & $0.77(0.43-1.38)$ \\
\hline \multicolumn{4}{|c|}{ Time from donation to start of insurance enrollment, years } \\
\hline$\leq 4.9$ (early) & 7.7 & 15.4 & $0.50(0.31-0.81)^{\mathrm{a}}$ \\
\hline$>4.9$ (later) & 19.3 & 14.4 & $1.33(0.91-1.96)$ \\
\hline \multicolumn{4}{|l|}{ Gout medication } \\
\hline Overall & 9.6 & 10.7 & $0.90(0.63-1.27)$ \\
\hline \multicolumn{4}{|l|}{ Sex } \\
\hline Men & 17.3 & 19.0 & $0.91(0.62-1.33)$ \\
\hline Women & 3.2 & 3.8 & $0.85(0.38-1.89)$ \\
\hline \multicolumn{4}{|c|}{ Time from donation to start of insurance enrollment, years } \\
\hline$\leq 4.9$ (early) & 5.3 & 9.9 & $0.53(0.30-0.96)^{\mathrm{a}}$ \\
\hline$>4.9$ (later) & 14.1 & 11.5 & $1.22(0.79-1.90)$ \\
\hline
\end{tabular}

When the components of the primary outcome were examined separately, age remained a significant risk factor, with each increase in year of donor age resulting in a $6 \%$ increase in risk of a gout diagnosis (aHR 1.06; 95\% CI $1.03-1.08 ; \mathrm{p}<0.0001$ ) and a $5 \%$ increase in risk of receiving a medication for gout (aHR 1.05; 95\% CI 1.02-1.08; $\mathrm{p}=0.0006$ ) (table 1). Similarly, male donors were more than three times as likely as female donors to receive a gout diagnosis (aHR 3.48; 95\% CI 2.07-5.88; $\mathrm{p}<0.0001$ ) and almost five times as likely to receive a medication for gout (aHR 4.75; 95\% CI 2.37-9.52). When examined separately, there were trends toward more gout diagnoses (aHR 1.68) and the use of gout medications (aHR 1.69) among African American donors compared with Caucasian donors, although these patterns were not statistically significant.

\section{Comparison of Gout in Living Donors and General Non-Donors}

In the matched-pairs comparisons, gout occurred at a rate of 16.0 per 1,000 person-years in living kidney donors compared with a statistically similar rate of $18.6 \mathrm{per}$ 1,000 person-years in the age- and sex-matched non-donors (rate ratio 0.86 ; 95\% CI 0.66-1.13) (table 2). When examined separately, rates of gout diagnoses and treatments also did not differ among donors compared with matched non-donors (table 2). Specifically, a diagnosis of gout alone occurred at a rate of 13.4 per 1,000 personyears in living kidney donors compared to 15.0 per 1,000 person-years in matched non-donors (rate ratio 0.89; 95\% CI 0.67-1.20). A pharmacy fill for a medication used 
to treat gout occurred at a rate of 9.6 per 1,000 personyears in donors compared to 10.7 per 1,000 person-years in matched non-donors (rate ratio 0.90; 95\% CI 0.631.27).

A diagnosis of gout and/or a pharmacy fill for a gout medication was more common among men compared to women in both donors and general non-donors, such that the donor-to-control rate ratios were similar to the rate ratios among the full sample when stratified by sex. Stratifying the donor cohort by time from nephrectomy to insurance enrollment demonstrated that gout rates were significantly lower among donors compared with general non-donors in those captured before the median time to enrollment (rate ratio $0.58 ; 95 \%$ CI 0.38-0.88) (fig. 1). Gout rates were higher among donors captured later after nephrectomy, and statistically similar to that among non-donors (rate ratio 1.15; 95\% CI 0.81-1.63). Parallel patterns of lower rates of gout diagnoses or treatment (examined separately) were observed among donors captured earlier, compared with later, after donation (table 2).

\section{Correlations of Gout and Renal Conditions after Living Donation}

Donors with gout had more frequent post-donation renal diagnoses compared to a sample of donors without gout, matched 1:3 by age, sex and race (fig. 2 ). These patterns reached statistical significance for acute kidney failure (rate ratio $12.5 ; 95 \%$ CI 1.5-107.0), CKD (rate ratio 5.0; 95\% CI 2.1-11.7), and other disorders of the kidney (rate ratio 2.3 ; 95\% CI 1.2-4.2). Renal diagnosis rates among living kidney donors with gout did not differ significantly from that of non-donors with gout, matched 1:3 by age and sex (online suppl. Appendix 3 ).

\section{Discussion}

We examined a linkage of OPTN registry data for living kidney donors with medical and pharmacy claims from a U.S. private health insurer to assess post-donation gout among living donors, explore possible within-donor demographic variation, compare gout rates among donors and general population non-donors, and examine renal condition rates among donors with and without gout. Based on this unique information source, we observed several key findings. First, within the living donor sample, African Americans had nearly twice the likelihood of post-donation gout diagnosis or treatment as Caucasians after adjustment for age and sex (4.4 vs. 2.4\%

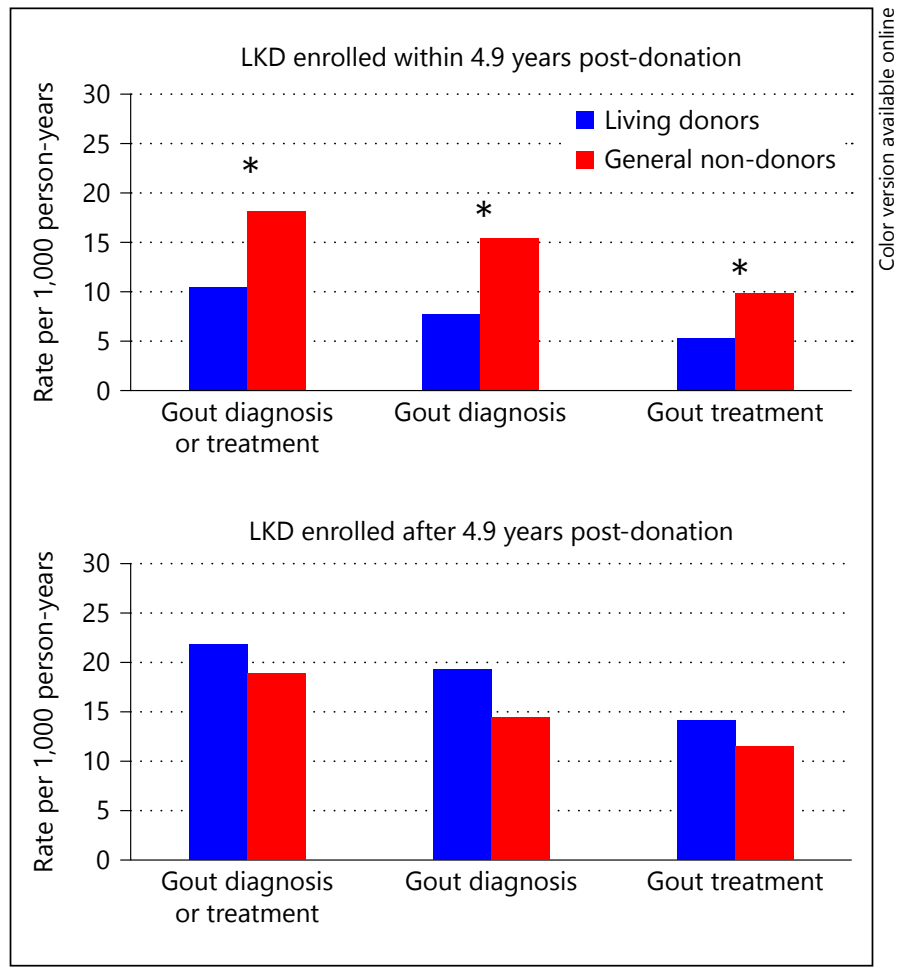

Fig. 1. Rates of gout among living kidney donors (LKD) compared with age- and sex-matched general non-donor controls, stratified by time from donation to study enrollment as below or above the sample median. ${ }^{*} \mathrm{p}<0.05$.

at seven years). Gout was also more common among older and male donors, consistent with patterns observed in the general population $[22,23]$ and in a recent Canadian study of living kidney donors [12]. Second, as an explicitly defined 'general population' comparison, we found a reduced rate of gout among living donors compared to general non-donors that was limited to donors with earlier capture in relation to donation, suggesting that an initial protective effect of donor medical evaluation and selection on the risk of gout dissipates with time after donation. Third, donors with gout had a higher burden of renal conditions after donation compared to matched donors without gout.

Gout affects more than 8 million Americans and can lead to significant morbidity including decrements in physical functioning, productivity and quality of life, as well as increased healthcare utilization and costs [24-27]. In 2008, gout-related emergency room costs in the U.S. were estimated to be $\$ 166$ million, and increased from $\$ 128$ million in 2006 [24]. The incidence and prevalence of gout are increasing and remain of particular concern in the elderly and in patients with CKD. A reduction in 
Fig. 2. Post-donation renal diagnosis rates among living kidney donors (LKD) with and without gout, matched 1:3 by age, sex and race. ${ }^{*} \mathrm{p}<0.05$.

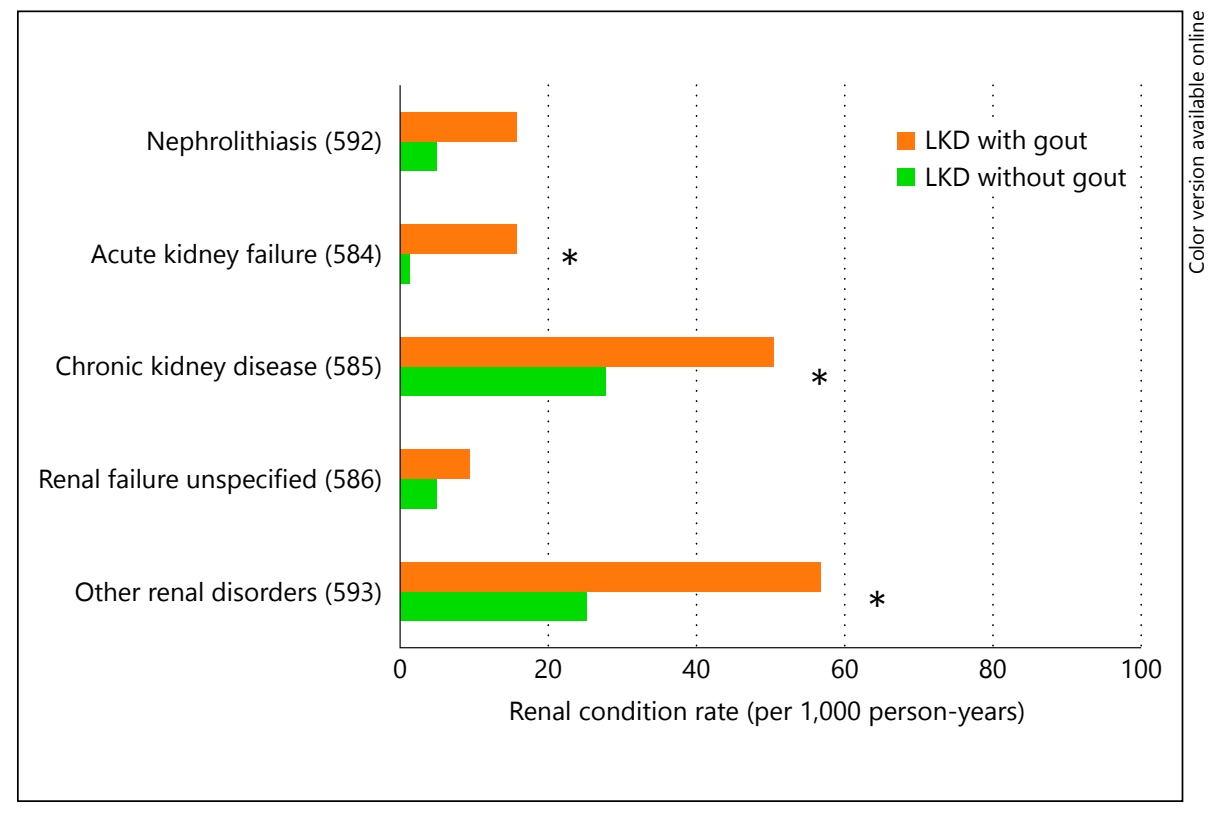

kidney function can lead to elevated serum uric acid levels and increased risk of gout (10-year gout incidence is estimated to be $49 \%$ for uric acid levels $\geq 9 \mathrm{mg} / \mathrm{dl}$ vs. $1 \%$ for uric acid levels $<7.0 \mathrm{mg} / \mathrm{dl}$ ) [1, 2, 28].

As more than 27,000 living kidney donations occur worldwide every year, there is a growing need to understand long-term health outcomes and healthcare resource needs in the donor population $[29,30]$. Whether surgically induced reduction in renal function in otherwise healthy persons contributes to similar clinical outcomes seen in patients with CKD is a topic of active debate [31, 32]. Recent studies have identified higher serum uric acid levels in living kidney donors compared to pre-donation levels $[9,10]$. We recently found that living kidney donors in Ontario, Canada have increased risk of a diagnosis of gout and prescribed gout treatment compared to matched non-donors screened for baseline good health [12]. However, associations of race with post-donation gout have not been described due to lack of data (including lack of race information in the Ontario study). The current study extends our previous work by assessing within-donor racial variation in post-donation gout, the overall incidence of gout in donors compared to general population controls, and the burden of renal conditions in donors with and without gout.

An understanding of racial variation in living donor outcomes is important given previous studies in the general population showing that African Americans have a higher risk of gout compared to Caucasians $[13,14]$. The higher risk of gout among African Americans may be attributable to the higher prevalence of risk factors for gout [33], such as hyperuricemia [27, 28], hypertension [14, 34], diuretic use [14], and CKD [3]. Hyperuricemia in African Americans may be due to polymorphisms in specific genomic loci [35-37]. We hypothesized that similar factors may mediate risks of gout after kidney donation. Although all donors undergo evaluation and selection for baseline good health including assessment of blood pressure and renal function, we have previously found that African American donors, compared with Caucasian donors, have a higher risk of hypertension and CKD after donation $[16,19]$.

When describing health outcomes to potential living kidney donors, important perspectives include overall event frequencies after donation, within-donor comparisons across donor sub-groups such as race, comparisons of outcomes among donors vs. the general population, and when possible, comparisons of outcomes among donors vs. selected non-donors with similar baseline health (table 3) [20,38]. Due to the rigorous evaluation that donors undergo as part of the selection process, living kidney donors are inherently healthier than the general population, contributing to superior outcomes usually seen in most studies comparing these two populations (e.g. overall survival, $\mathrm{CKD}$, end-stage renal disease, diabetes) [39-43]. In the current study, we found a reduced rate of gout among living donors compared to general non-donors that was limited to donors captured earlier in rela- 
Table 3. Perspectives of risk related to gout among living kidney donors ${ }^{\mathrm{a}}$

\begin{tabular}{|c|c|c|c|c|c|c|}
\hline \multirow[t]{2}{*}{ Risk perspective } & \multirow[t]{2}{*}{ Metric } & \multirow[t]{2}{*}{ Examples } & \multicolumn{4}{|c|}{ Estimates of risk } \\
\hline & & & $\begin{array}{l}\text { United States }{ }^{\mathrm{b}} \\
\text { donors }\end{array}$ & & $\begin{array}{l}\text { Canadian }{ }^{\mathrm{c}} \\
\text { donors }\end{array}$ & \\
\hline \multirow[t]{2}{*}{ Descriptive } & $\begin{array}{l}\text { Frequency of events after } \\
\text { donation }\end{array}$ & $\begin{array}{l}\text { Frequency of gout after } \\
\text { donation }\end{array}$ & $2.5 \%{ }^{\mathrm{d}}$ & & $3.4 \%^{\mathrm{e}}$ & \\
\hline & & & $\begin{array}{l}\text { African American } \\
\text { donors }\end{array}$ & $\begin{array}{l}\text { Caucasian } \\
\text { donors }^{\mathrm{d}}\end{array}$ & $\begin{array}{l}\text { African American } \\
\text { donors }\end{array}$ & $\begin{array}{l}\text { Caucasian } \\
\text { donors }\end{array}$ \\
\hline \multirow[t]{2}{*}{$\begin{array}{l}\text { Comparative, } \\
\text { within-donor }\end{array}$} & $\begin{array}{l}\text { Relative outcomes in donor } \\
\text { subgroups }\end{array}$ & $\begin{array}{l}\text { Differences in gout among } \\
\text { African American vs. } \\
\text { Caucasian donors }\end{array}$ & $\begin{array}{l}4.4 \%^{\mathrm{d}} \\
\text { Hazard ratio } 1.8(9 \\
\mathrm{p}=0.04\end{array}$ & $\begin{array}{l}2.4 \% \mathrm{~d} \\
\% \text { CI } 1.0-3.2)\end{array}$ & NA & NA \\
\hline & & & Donors & Non-donors & Donors & Non-donors \\
\hline $\begin{array}{l}\text { Comparative, } \\
\text { donor vs. general } \\
\text { non-donor }\end{array}$ & $\begin{array}{l}\text { Relative outcomes in donors } \\
\text { vs. general population (often } \\
\text { demographically matched, but } \\
\text { not screened for baseline health } \\
\text { status) }\end{array}$ & $\begin{array}{l}\text { Differences in gout among } \\
\text { living donors vs. general } \\
\text { population non-donors }\end{array}$ & $\begin{array}{l}16.0 \text { per } \\
1,000 \mathrm{PY} \\
\text { Rate ratio } 0.86\left(95^{\circ}\right.\end{array}$ & $\begin{array}{c}18.6 \text { per } \\
1,000 \mathrm{PY} \\
\text { CI } 0.7-1.3)\end{array}$ & $\begin{array}{l}3.4 \% \mathrm{e}^{\mathrm{e}} \\
\text { Hazard ratio } 1.2(9 \\
\mathrm{p}=0.1\end{array}$ & $\begin{array}{l}2.7 \% \\
\% \text { CI } 0.9-1.6)\end{array}$ \\
\hline $\begin{array}{l}\text { Attributable, } \\
\text { donor vs. highly } \\
\text { selected } \\
\text { non-donor }\end{array}$ & $\begin{array}{l}\text { Relative outcomes in donors } \\
\text { vs. persons who would } \\
\text { otherwise meet donor selection } \\
\text { criteria (designed to simulate } \\
\text { counter-factual experience of } \\
\text { life without donation) }\end{array}$ & $\begin{array}{l}\text { Differences in gout among } \\
\text { living donors vs. } \\
\text { non-donors selected for } \\
\text { baseline good health }\end{array}$ & NA & NA & $\begin{array}{l}3.4 \% \mathrm{e}^{\mathrm{e}} \\
\text { Hazard ratio } 1.6(9 \\
\mathrm{p}<0.001\end{array}$ & $\begin{array}{l}2.0 \% \\
\% \text { CI } 1.2-2.1)\end{array}$ \\
\hline
\end{tabular}

${ }^{a}$ Modified with permission from Lentine at al. [20]. ${ }^{\mathrm{b}}$ Data from the current study estimating the risk of gout diagnosis based on healthcare administrative database claims or pharmacy fills for a medication used to treat gout. ${ }^{c}$ Data from Lam et al. estimating the risk of gout diagnosis based on healthcare administrative database claims [12]. ${ }^{\mathrm{d}}$ Cumulative incidence at seven years post-donation. ${ }^{\mathrm{e}}$ Median follow-up of living kidney donors was 8.4 years. CI $=$ Confidence interval; NA = not applicable; PY = person-years.

tion to donation, suggesting that a protective effect of medical screening and selection on risk of gout dissipates with time after donation. When living kidney donors were compared to non-donors selected for similar baseline health in Ontario, their risk of gout appears to be higher [12], supporting that surgical GFR reduction is relevant to uric acid metabolism and associated clinical consequences. Framing post-donation gout rates against an age- and sex-matched general population (without medical screening) in the current study provides an additional benchmark, and shows that gout among donors within the study observation period does not exceed that of the general population. Future investigation is warranted to determine whether the attributable impact of donation on gout risk (i.e., compared to otherwise healthy persons) differs according to race and other demographic traits.

When donors with gout were compared to donors without gout, there were significant increases in the rates of post-donation renal conditions, such as acute kidney failure, $\mathrm{CKD}$, and other disorders of the kidney. This question was examined with a correlational, rather than temporally restricted design, because of circularity in associations of gout and kidney dysfunction as well as the duration of available claims data. Although CKD can lead to hyperuricemia (from impaired uric acid excretion), more recently, it has been suggested that uric acid may, itself, contribute to the development and progression of CKD [4-7]. Notably, a recent pilot study found that higher pre-donation serum uric acid was associated with larger GFR reductions at 6 months post-donation among women [15]. Our results suggest that living donors who develop gout also have a higher burden of renal conditions compared to donors without gout, although the mechanisms of this observation warrant additional investigation, ideally in studies including laboratory data. While we did not have sufficient sample size to examine racial variation in renal conditions among the subgroup who developed gout, higher risks of post-donation renal 
conditions have been demonstrated among African American donors when compared with Caucasian donors $[16,19,21,44]$. Racial differences in renal risk are likely multifactorial and impacted by racial variation in the onset of comorbidities such as hypertension and diabetes after donation $[16,19]$ and in the distribution of genetic variants in renal risk allelles such as apolipoprotein-L1 $[45,46]$. The current study also supports a need for further study of a possible contribution of gout to the risk of renal dysfunction among African American kidney donors.

There are limitations to our study. We relied on administrative data from a private insurance plan, and thus, uninsured living kidney donors are not captured. We were reassured by the similarities in baseline characteristics between our cohort and the entire donor population captured in the OPTN [16]. Pre-donation benefits were captured for only a minority of the donors $(7.7 \%)$, and thus, information on pre-donation diagnoses, such as gout, was not adequate for inclusion. Due to the nature of OPTN collection of baseline donor data, we also lacked information on clinical parameters such as body mass index sufficient for inclusion (available for only 5.3\% of sample), and the OPTN does not collect information on pre-donation gout history. Laboratory values, such as serum uric acid levels and post-donation serum creatinine, and information on dietary habits, alcohol intake, and over-the-counter medication use were not available in our data sources. Our outcome definition of a diagnosis of gout was based on provider-reported billing claims, rather than joint fluid aspiration for monosodium urate crystals, and may be subject to misclassification. However, patterns based on gout diagnoses and gout treatments were similar. We did not account for the number of physician visits in follow-up, although in the Canadian study adjustments for physician visits did not appreciably change the results or inferences [12]. Lastly, race information was not available for non-donors; however, since $13 \%$ of the donors in our study were African American (similar to the proportion of African Americans in the general U.S. population), African American representation is unlikely to have produced substantial overestimates of gout in the non-donors.

Despite limitations, contributions of the current study include the ability to link national donor registry data with medical billing and pharmacy fill records to follow outcomes not captured in the registry among more than 4,000 living kidney donors. Unlike the Canadian study, we were able to assess pharmacy fill claims for the entire cohort and not just for those older than 65 years who are eligible for provincial drug coverage [12]. Electronic pharmacy fill claims have been shown to be highly accurate records of physician prescribing $[47,48]$. To our knowledge, this is the first study to assess racial variation in the risk of gout in living kidney donors. Demonstration of diagnosis patterns and treatment requirements of insured donors to manage comorbidities, regardless of direct impact of donation itself, supports the need for longterm post-donation follow-up and access to healthcare for all donors. Gibney et al. reported that, overall, $18 \%$ of living donors in a recent U.S. sample lacked insurance at donation, and insurance access varied demographically, such that $30-40 \%$ of young, African American male donors were uninsured [49]. Further, follow-up reporting deficiencies by U.S. centers are greater in these groups [50]. A commitment to follow-up and basic healthcare access is critical so that donors who have or develop conditions such as gout can be recognized and treated.

In conclusion, we found that donor subgroups at increased risk of gout include African Americans, older donors, and men. Donors have lower gout rates than general population non-donors early after donation but similar rates during later observation, suggesting that an initial protective effect of medical evaluation and selection on gout risk dissipates with time after donation. Donors with gout also appear to have a higher burden of post-donation renal complications after demographic adjustment. We strongly support the practice of living kidney donation, a practice that substantially benefits patients with end-stage renal disease, their support networks, and society. Better understanding of health outcomes and pharmaceutical care needs in this patient population improves the donor consent process, and guides recommendations for monitoring and management. Demonstration of comorbidities and related treatment requirements among insured donors supports the importance of long-term follow-up and healthcare access for all living donors. Given the recent evidence that donation may increase the risk of gout over that experienced by healthy non-donors, and the current findings of within-donor demographic variation in gout risk, future studies should examine whether the direct impacts of donation on the risk and consequences of gout differ according to demographic traits.

\section{Acknowledgments}

This work was supported in part by grants from the National Institutes of Health (NIH)/National Institute of Diabetes and Digestive and Kidney Diseases (NIDDK) R01-DK096008 and K24- 
DK101828. Data reported here have been supplied by the United Network for Organ Sharing (UNOS) as the contractor for the Organ Procurement and Transplantation Network (OPTN). The interpretation and reporting of these data are the responsibility of the authors and in no way should be seen as an official policy of or interpretation by the OPTN, the U.S. Government, the Department of Defense, the NIDDK or the National Institutes of Health. NNL was supported by the Clinical Investigator Program at Western University and by a KRESCENT postdoctoral fellowship award. AXG received investigator-initiated grants from Astellas and Roche to support a CIHR-funded prospective study on living kidney donation, and is also supported by a Canadian Institutes of
Health Research Clinician-Scientist Award. The opinions, results, and conclusions reported in this article are those of the authors and are independent of the funding sources.

\section{Disclosure Statement}

The authors have no conflicts of interest related to this work. This work was supported by grants from the National Institutes of Health (NIH)/National Institute of Diabetes and Digestive and Kidney Diseases (NIDDK) R01-DK096008 and K24-DK101828.

\section{References}

1 Lipkowitz MS: Regulation of uric acid excretion by the kidney. Curr Rheumatol Rep 2012; 14:179-188.

2 Krishnan E: Reduced glomerular function and prevalence of gout: NHANES 2009-10. PLoS One 2012;7:e50046.

-3 Krishnan E: Chronic kidney disease and the risk of incident gout among middle-aged men: a seven-year prospective observational study. Arthritis Rheum 2013;65:3271-3278.

-4 Chou YC, Kuan JC, Yang T, Chou WY, Hsieh PC, Bai CH, et al: Elevated uric acid level as a significant predictor of chronic kidney disease: a cohort study with repeated measurements. J Nephrol 2014, Epub ahead of print.

$\checkmark 5 \mathrm{Li} \mathrm{L}$, Yang C, Zhao Y, Zeng X, Liu F, Fu P: Is hyperuricemia an independent risk factor for new-onset chronic kidney disease?: a systematic review and meta-analysis based on observational cohort studies. BMC Nephrol 2014; 15:122.

-6 Johnson RJ, Nakagawa T, Jalal D, SánchezLozada LG, Kang DH, Ritz E: Uric acid and chronic kidney disease: which is chasing which? Nephrol Dial Transplant 2013;28: 2221-2228.

7 Dousdampanis P, Trigka K, Musso CG, Fourtounas $\mathrm{C}$ : Hyperuricemia and chronic kidney disease: an enigma yet to be solved. Ren Fail 2014;36:1351-1359.

8 Garg AX, Muirhead N, Knoll G, Yang RC, Prasad GV, Thiessen-Philbrook H, et al: Proteinuria and reduced kidney function in living kidney donors: a systematic review, metaanalysis, and meta-regression. Kidney Int 2006;70:1801-1810.

\9 Rossi M, Campbell KL, Johnson DW, Stanton T, Haluska BA, Hawley CM, et al: Uremic toxin development in living kidney donors: a longitudinal study. Transplantation 2014;97: 548-554.

10 Kasiske BL, Anderson-Haag T, Ibrahim HN, Pesavento TE, Weir MR, Nogueira JM, et al: A prospective controlled study of kidney donors: baseline and 6-month follow-up. Am J Kidney Dis 2013;62:577-586.

11 Hida M, Iida T, Shimbo T, Shiramizu T, Nakamura K, Saitoh H, et al: Renal function after nephrectomy in renal donors. Tokai J Exp Clin Med 1982;7:511-516.

12 Lam NN, Mcarthur E, Kim SJ, Prasad GV, Lentine KL, Reese PP, et al: Gout after living kidney donation: a matched cohort study. Am J Kidney Dis 2015, in press.

13 Singh JA: Racial and gender disparities among patients with gout. Curr Rheumatol Rep 2013; 15:307.

14 Maynard JW, McAdams-DeMarco MA, Law A, Kao L, Gelber AC, Coresh J, et al: Racial differences in gout incidence in a populationbased cohort: Atherosclerosis Risk in Communities Study. Am J Epidemiol 2014;179: 576-583.

15 Cho A, Lee JE, Jang HR, Huh W, Kim DJ, Oh $\mathrm{HY}$, et al: Association between pre-donation serum uric acid concentration and change in renal function after living kidney donation in women. Intern Med J 2014;44:1217-1222.

16 Lentine KL, Schnitzler MA, Xiao H, Saab G, Salvalaggio PR, Axelrod D, et al: Racial variation in medical outcomes among living kidney donors. N Engl J Med 2010;363:724-732.

17 Lentine KL, Schnitzler MA, Xiao H, Axelrod D, Davis CL, McCabe M, et al: Depression diagnoses after living kidney donation: linking U.S. Registry data and administrative claims. Transplantation 2012;94:77-83.

$\checkmark 18$ Lentine KL, Vijayan A, Xiao H, Schnitzler MA, Davis CL, Garg AX, et al: Cancer diagnoses after living kidney donation: linking U.S. Registry data and administrative claims. Transplantation 2012;94:139-144.

19 Lentine KL, Schnitzler MA, Xiao H, Axelrod D, Garg AX, Tuttle-Newhall JE, et al: Consistency of racial variation in medical outcomes among publicly and privately insured living kidney donors. Transplantation 2014;97:316324.

20 Lentine KL, Schnitzler MA, Garg AX, Xiao H, Axelrod D, Tuttle-Newhall JE, et al: Understanding antihypertensive medication use after living kidney donation through linked national registry and pharmacy claims data. Am J Nephrol 2014;40:174-183.

21 Lentine KL, Schnitzler MA, Garg AX, Xiao H, Axelrod D, Tuttle-Newhall JE, et al: Race, rela- tionship and renal diagnoses after living kidney donation. Transplantation 2015, in press.

22 Wallace KL, Riedel AA, Joseph-Ridge N, Wortmann R: Increasing prevalence of gout and hyperuricemia over 10 years among older adults in a managed care population. J Rheumatol 2004;31:1582-1587.

23 Chen JH, Yeh WT, Chuang SY, Wu YY, Pan WH: Gender-specific risk factors for incident gout: a prospective cohort study. Clin Rheumatol 2012;31:239-245.

24 Garg R, Sayles HR, Yu F, Michaud K, Singh J, Saag KG, et al: Gout-related health care utilization in US emergency departments, 2006 through 2008. Arthritis Care Res (Hoboken) 2013;65:571-577.

25 Smith E, Hoy D, Cross M, Merriman TR, Vos $\mathrm{T}$, Buchbinder R, et al: The global burden of gout: estimates from the global burden of disease 2010 study. Ann Rheum Dis 2014;73: 1470-1476

26 Wertheimer A, Morlock R, Becker MA: A revised estimate of the burden of illness of gout. Curr Ther Res Clin Exp 2013;75:1-4.

27 Zhu Y, Pandya BJ, Choi HK: Prevalence of gout and hyperuricemia in the US general population: the national health and nutrition examination survey 2007-2008. Arthritis Rheum 2011;63:3136-3141.

28 Campion EW, Glynn RJ, DeLabry LO: Asymptomatic hyperuricemia. Risks and consequences in the Normative Aging Study. Am J Med 1987;82:421-426.

29 Horvat LD, Shariff SZ, Garg AX: Global trends in the rates of living kidney donation. Kidney Int 2009;75:1088-1098.

-30 Leichtman A, Abecassis M, Barr M, Charlton $\mathrm{M}$, Cohen D, Confer D, et al: Living kidney donor follow-up: state-of-the-art and future directions, conference summary and recommendations. Am J Transplant 2011;11:2561-2568.

31 Srinivas TR, Poggio ED: Do living kidney donors have CKD? Adv Chronic Kidney Dis 2012;19:229-236.

32 Matas AJ, Ibrahim HN: The unjustified classification of kidney donors as patients with CKD: critique and recommendations. Clin J Am Soc Nephrol 2013;8:1406-1413. 
33 Krishnan E: Gout in African Americans. Am J Med 2014;127:858-864.

-34 McAdams-DeMarco MA, Maynard JW, Baer AN, Coresh J: Hypertension and the risk of incident gout in a population-based study: the Atherosclerosis Risk in Communities Cohort. J Clin Hypertens (Greenwich) 2012;14:675-679.

35 Dehghan A, Kottgen A, Yang Q, Hwang SJ, Kao WL, Rivadeneira F, et al: Association of three genetic loci with uric acid concentration and risk of gout: a genome-wide association study. Lancet 2008;372:1953-1961.

-36 Charles BA, Shriner D, Doumatey A, Chen G, Zhou J, Huang $\mathrm{H}$, et al: A genome-wide association study of serum uric acid in African Americans. BMC Med Genomics 2011;4:17.

- 37 Tin A, Woodward OM, Kao WH, Liu CT, Lu X, Nalls MA, et al: Genome-wide association study for serum urate concentrations and gout among African Americans identifies genomic risk loci and a novel URAT1 loss-of-function allele. Hum Mol Genet 2011;20:4056-4068.

38 Lam NN, Lentine KL, Garg AX: End-stage renal disease risk in live kidney donors: what have we learned from two recent studies? Curr Opin Nephrol Hypertens 2014;23:592-596.
Fehrman-Ekholm I, Elinder CG, Stenbeck M, Tyden G, Groth CG: Kidney donors live longer. Transplantation 1997;64:976-978.

40 Fehrman-Ekholm I, Duner F, Brink B, Tyden G, Elinder CG: No evidence of accelerated loss of kidney function in living kidney donors: results from a cross-sectional follow-up. Transplantation 2001;72:444-449.

41 Mjøen G, Reisaeter A, Hallan S, Line PD, Hartmann A, Midtvedt K, et al: Overall and cardiovascular mortality in Norwegian kidney donors compared to the background population. Nephrol Dial Transplant 2012;27: 443-447.

42 Ibrahim HN, Foley R, Tan L, Rogers T, Bailey $\mathrm{RF}$, Guo $\mathrm{H}$, et al: Long-term consequences of kidney donation. N Engl J Med 2009;360: 459-469.

43 Ibrahim HN, Kukla A, Cordner G, Bailey R, Gillingham K, Matas AJ: Diabetes after kidney donation. Am J Transplant 2010;10:331337.

44 Muzaale AD, Massie AB, Wang MC, Montgomery RA, McBride MA, Wainright JL, et al: Risk of end-stage renal disease following live kidney donation. JAMA 2014;311:579-586.
Friedman DJ, Kozlitina J, Genovese G, Jog P, Pollak MR: Population-based risk assessment of APOL1 on renal disease. J Am Soc Nephrol 2011;22:2098-2105.

46 Parsa A, Kao WH, Xie D, Astor BC, Li M, Hsu $\mathrm{CY}$, et al: APOL1 risk variants, race, and progression of chronic kidney disease. N Engl J Med 2013;369:2183-2196.

47 Levy AR, O’Brien BJ, Sellors C, Grootendorst $\mathrm{P}$, Willison D: Coding accuracy of administrative drug claims in the Ontario drug benefit database. Can J Clin Pharmacol 2003;10: 67-71.

48 Lau HS, de Boer A, Beuning KS, Porsius A: Validation of pharmacy records in drug exposure assessment. J Clin Epidemiol 1997;50: 619-625.

49 Gibney EM, Doshi MD, Hartmann EL, Parikh CR, Garg AX: Health insurance status of US living kidney donors. Clin J Am Soc Nephrol 2010;5:912-916.

50 Ommen ES, LaPointe Rudow D, Medapalli RK, Schroppel B, Murphy B: When good intentions are not enough: obtaining follow-up data in living kidney donors. Am J Transplant 2011;11:2575-2581. 